\title{
The Public Health Innovation Model: Merging Private Sector Processes with Public Health Strengths
}

\author{
Cameron Lister ${ }^{1}$, Hannah Payne ${ }^{1}$, Carl L. Hanson ${ }^{1 *}$, Michael D. Barnes ${ }^{1}$, Siena F. Davis ${ }^{1}$ \\ and Todd Manwaring ${ }^{2}$
}

${ }^{1}$ Department of Health Science, Brigham Young University, Provo, UT, United States, ${ }^{2}$ Ballard Center for Economic Self-Reliance, Brigham Young University, Provo, UT, United States

Public health enjoyed a number of successes over the twentieth century. However, public health agencies have arguably been ill equipped to sustain these successes and address the complex threats we face today, including morbidity and mortality associated with persistent chronic diseases and emerging infectious diseases, in the context of flat funding and new and changing health care legislation. Transformational leaders, who are not afraid of taking risks to develop innovative approaches to combat

OPEN ACCESS

Edited by:

Rosemary M. Caron,

University of New Hampshire,

United States

Reviewed by:

Geraldine Sanchez Aglipay, University of Illinois at Chicago, United States

Preeti Negandhi, Indian Institute of Public Health,

India

*Correspondence:

Carl L. Hanson

carl_hanson@byu.edu

Specialty section: This article was submitted to Public Health Education and Promotion, a section of the journal Frontiers in Public Health

Received: 24 March 2017 Accepted: 18 July 2017

Published: 07 August 2017

Citation:

Lister C, Payne H, Hanson CL, Barnes MD, Davis SF and Manwaring T (2017) The Public

Health Innovation Model: Merging Private Sector Processes with Public Health Strengths.

Front. Public Health 5:192. doi: 10.3389/fpubh.2017.00192 present-day threats, are needed within public health agencies. We propose the Public Health Innovation Model (PHIM) as a tool for public health leaders who wish to integrate innovation into public health practice. This model merges traditional public health program planning models with innovation principles adapted from the private sector, including design thinking, seeking funding from private sector entities, and more strongly emphasizing program outcomes. We also discuss principles that leaders should consider adopting when transitioning to the PHIM, including cross-collaboration, community buy-in, human-centered assessment, autonomy and creativity, rapid experimentation and prototyping, and accountability to outcomes.

Keywords: innovation, program planning, design thinking, leadership, private sector

\section{INTRODUCTION}

Recent achievements in public health have resulted in a 25 -year increase in average life expectancy in the United States (1). These advances were the result of changes in the public health system, including improved surveillance systems, advocacy for effective health policies, and epidemiologic studies which improved decision-making capabilities (2). However, declining public health resources and complex health threats may make it difficult for advances of the past century to be sustained.

Public health frameworks have neither changed in response to such threats nor adapted in the face of technological and cultural shifts. For example, public health's utilization of social media is inferior to fields such as business and marketing; while health departments have attempted to incorporate social media in practice, studies suggest that health professionals' capacity for using these tools to engage populations is low (3-5). Indeed, it has been suggested that the current public health system has "neither the organization nor the incentive to comprehensively address population-centered, primary prevention health services that are evidence-based or linked to improved health outcomes" (6).

The inability, or reluctance, to adopt major advancements and reconstruct frameworks in public health may be attributed to the legacy concept. This concept is the tendency for a successful 
organization to believe it is entitled to continued success; as a result, the organization can fail to seek new opportunities, hampering continued success (7). Contemporary public health problems "require a different set of tools which will only be used if the legacy concept in public health is replaced by a new attitude that encourages innovation, risk-taking, and the building of new partnerships" (6).

To combat increasingly complex public health threats, public health leaders should pursue new processes and implement innovative solutions. In particular, traditional public health planning models do not explicitly encourage innovation. While the private sector conventionally resorts to innovative thinking, experimentation, and risk-taking in the face of threats, this approach is not yet embraced in public health's program planning models. A new public health framework, which incorporates successful processes of the private sector and maximizes the strengths of the public sector, may be a major key to significant improvements in our most pressing and complex public health threats.

\section{TRADITIONAL PUBLIC HEALTH PLANNING MODELS}

In traditional public health planning models (see Figure 1), key characteristics are as follows:
1. Steps are linear, and solutions are often evidence based and preconceived before beginning the planning process. In these models, the goal of the health professional is not to generate novel solutions but to implement prescribed solutions in varying contexts.

2. Funding usually comes from government and public sources, such as the Prevention and Public Health Fund and state general funds (8). Public funding opportunities are often limited in availability and scope; consequently, practitioners may be constrained in the type and cost of programs they can implement.

3. Program outcomes are not strongly linked to funding allocation; while granting organizations do take into account program effectiveness, funding is usually allocated to organizations on a regular basis, independent of program outcomes.

Traditional public health planning models have been successful for many public health problems in the past. However, reliance on evidence-based practice and public funding, as well as neglecting to attend to program outcomes in allocating funding, can result in the de-emphasis of health outcomes in program implementation, and the long-term implementation of ineffective programs.

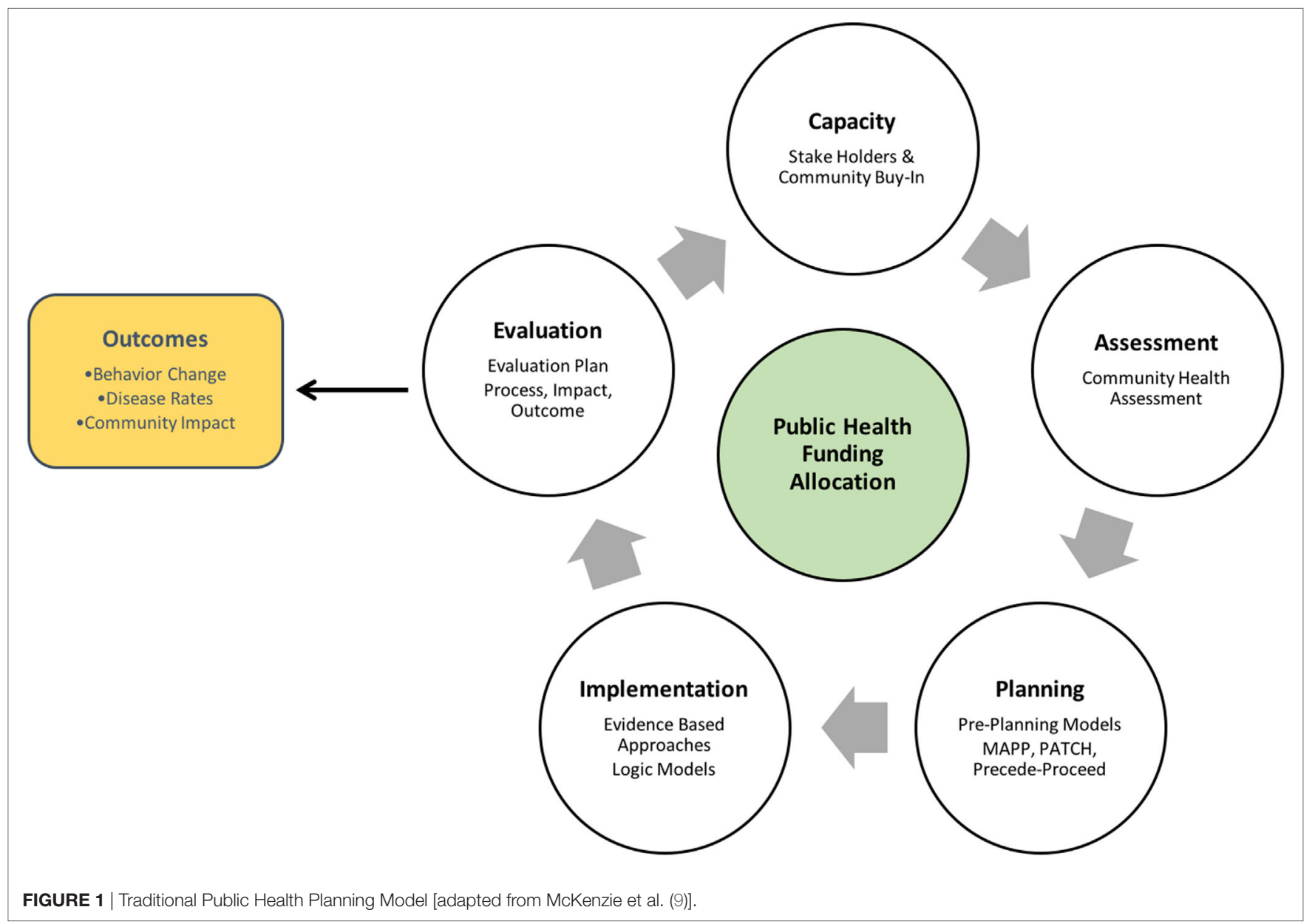




\section{LESSONS FROM THE PRIVATE SECTOR}

\section{Innovative Solutions}

A new planning model must incorporate a mechanism for generating innovative solutions. Design thinking (see Figure 2), a problem-solving technique widely embraced in the private sector, is one such process. It is an approach to solving problems that starts with the customer and is human centered, research based, collaborative and multidisciplinary, and iterative (10).

Design thinking is said to find more innovative solutions to problems in less time and with less expense than traditional methods by initiating a continuous joint discovery cycle between the client and practitioner. Shortly after this process, an inexpensive, rapid prototyping cycle is initiated that creates "touchable" solutions that the client can test. These two interconnected cycles are repeated until a desirable and viable (as determined by the client) solution is found. Only then does the practitioner implement the new solution $(10,11)$.

While design thinking has been implemented by a number of fields in the private sector, it is less commonly utilized in the public sector, including in public health. Public health may be better able to incorporate innovation in practice with the adoption of principles from design thinking. Indeed, Trowbridge (12) suggests that "public health is well-positioned to expand application of design thinking to include health promotion."

\section{Increase Funding from Private Entities}

Distinct in a new model must be the addition of public health startup funding from businesses and other private parties. Private funding is best allocated in the Prototype (or Implementation) mode (see Figure 2), in which practitioners propose and iterate smallscale program plans. Funders can then go on to implement

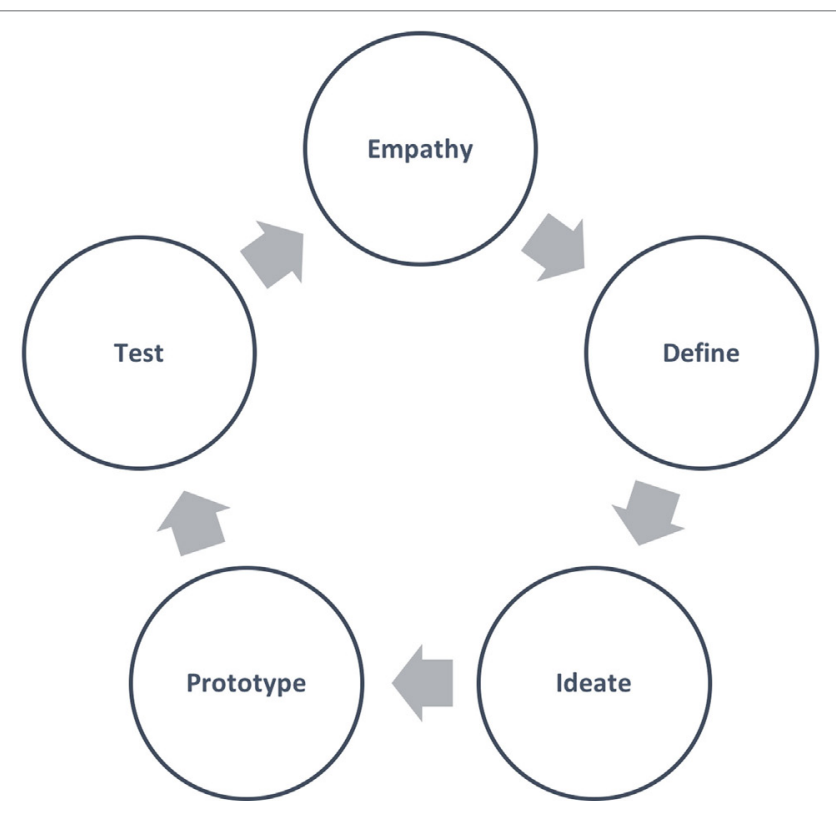

FIGURE 2 | Design thinking process. larger scale iterations of the most promising ideas proposed by practitioners.

Seeking funding from public sources may be a challenging shift for health practitioners, as the leading health issues may not be the primary interests of private funders. Questions associated with balancing the power and interests, including conflicts of interests, are important to consider when partnering with private funders. Leveraging appropriate resources using important precautions can be taken to weigh benefits with any risks that could exist. Examples of well-cited precautions include at least three papers that note key tests to balance the power and interests of public-private partnerships while also promoting the benefits, minimizing the risks associated with leveraging increasingly sustainable partnerships in communities (13-15). These partnerships in public health already exist, including in health product development $(16,17)$ and the strengthening of health services (18). More clearly linking funding to outcomes may also be helpful to find better ways for valuating and monetizing prevention.

Public health practitioners must learn to procure additional funding from private entities as public health is scaled up to address an increasing variety of health needs among diverse populations. Public health practitioners can leverage the corporate social responsibility (CSR) component of private entities to advance public health programs. CSR has been defined by the European Commission as "a concept whereby companies decide voluntarily to contribute to a better society and a cleaner environment" (19). Examples of CSR include Ben and Jerry's Caring Dairy program (a sustainability program for dairy farms) (20), Levi Strauss \& Co's Water $<$ Less $^{\mathrm{TM}}$ process (which has saved one billion liters of water since 2011) (21), and TOMS One for One ${ }^{\circledR}$ model (a model TOMS follows to provide shoes, sight, water, and safe birth services in return for every purchased product) (22).

Orlitzky et al. conducted a meta-analysis to understand the relationship between corporate social performance (CSP) and corporate financial performance (CFP) (23). Their findings suggest that there is a positive relationship between CSP and CFP. In other words, businesses that support social or environmental causes benefit though increased profits (23). In the context of public health, private organizations will likely provide continued funding to programs that help to fulfill their need for CSR and ultimately CFP.

\section{PUBLIC HEALTH INNOVATION MODEL (PHIM)}

The PHIM merges traditional public health planning models with lessons learned from the private sector (see Figure 3). The PHIM accomplishes this by integrating design thinking "modes" with traditional program planning stages, leveraging the use of private sectors resources, and focusing more closely on program outcomes.

The successful adoption of private sector strengths into public health planning models requires public health to adopt several key strategies that include cross-collaboration, community buyin, autonomy, and creativity. A discussion of these strategies and steps of the PHIM are discussed in more detail below. Examples of innovative public health approaches that incorporate these principles in practice can be found in Table 1 . 


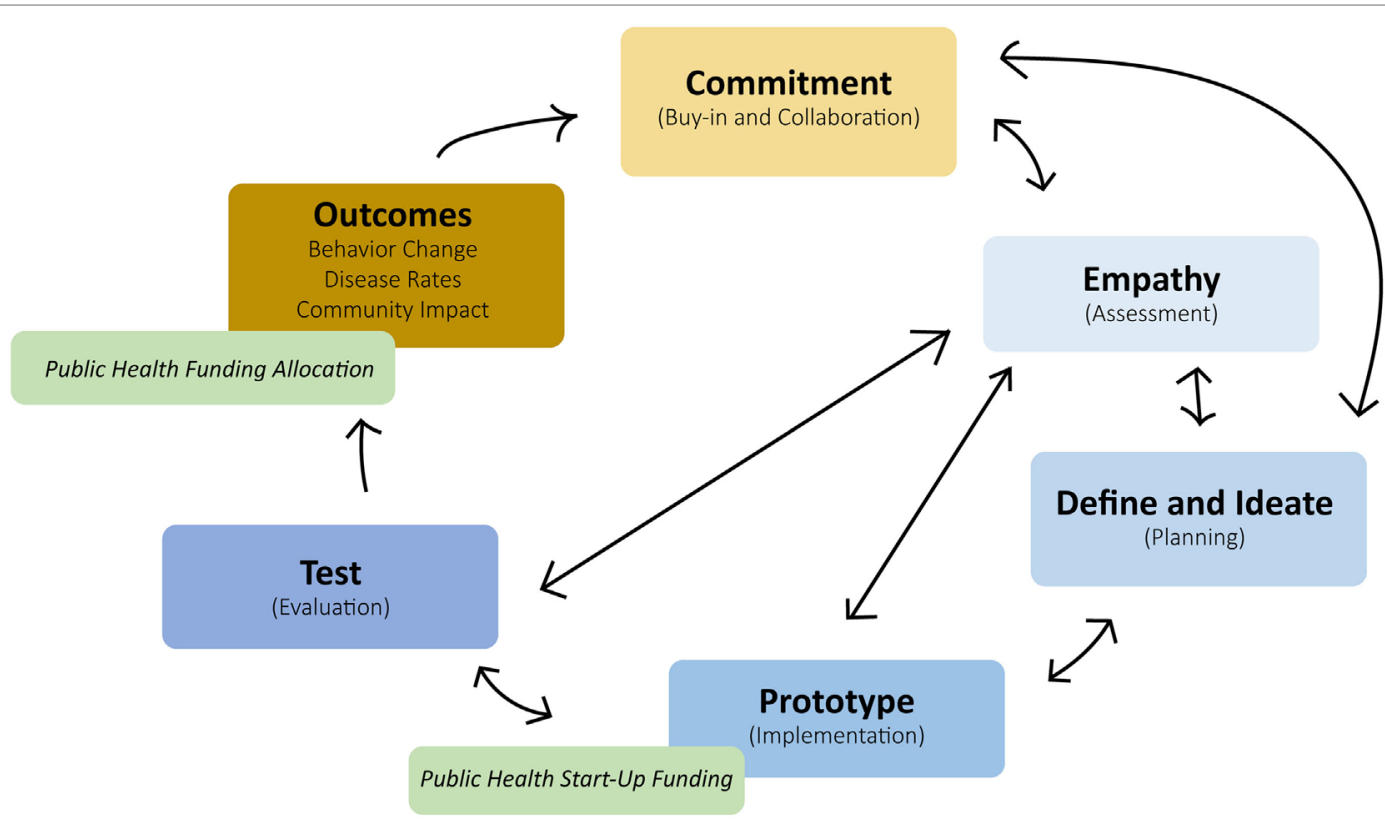

FIGURE 3 | Public Health Innovation Model.

\section{Commitment}

In the capacity-building stage of traditional models (Figure 1), public health agencies develop informal partnerships with stakeholders to form decision-making teams. In the PHIM, the commitment stage incorporates two design thinking components (cross-collaboration and community buy-in) that can help to formalize partnerships over time:

Cross-Collaboration: Public health has recognized the importance of coalition building and interorganizational networks to not only improve health but also obtain resources and buy-in (31). However, the PHIM suggests that a stronger emphasis should be placed on the importance of cross-silo collaborations through the application of systems thinking. Incorporating systems thinking requires (1) attention to relationships and an understanding of people, (2) specialized study to understand the parts of the public health system, (3) transcending traditional academic boundaries, and (4) matching public health problems to the appropriate method for studying them (32). While it may not be possible to completely eliminate silos within public health, systems thinking has helped public health practitioners recognize that it is "essential to link [silos] ... and recognize that they represent components of a larger system" (33).

Community Buy-in: Generating passion to solve community problems is a tenet of both design thinking and public health. When community members assemble together to tackle problems, the power of mobilization and local solutions begins to take place. Such grassroots efforts are typically more sustainable than top-down strategies employed by experts with little community involvement. Public health practitioners who are committed to community mobilization have learned to balance the use of best practice evidence while allowing for local innovation and creativity $(34,35)$. While community buy-in has been successfully implemented in recent health interventions $(36,37)$, successful long-term assessment is uncommon.

When approaching community buy-in using the PHIM, two principles can be adopted to increase success. First, public health can learn from businesses' success in creating demand. Businesses typically achieve success by identifying a pain and then addressing that pain in such a way that the public becomes enthusiastic enough about the solution that they are willing to pay for it. Public health relies heavily on the free distribution of services, regardless of demand. Although this is unsurprising, as populations served are often economically disadvantaged, generating solutions to health pains similar to private organizations can be implemented by public health organizations. While there is much debate globally concerning the efficacy of charging for preventive health services, particularly in lower and middle income countries, in some cases, underserved populations may not view free services as valuable (38) and charging small, reasonable fees for health services may not negatively affect demand $(39,40)$. While there are limitations to charging for health services and instances in which this is inappropriate, creating the kind of demand typical in the private sector should be attempted more frequently.

Second, public health organizations should study and incorporate business models of innovation into practice, especially the Diffusion of Innovation Theory (41). This model seeks to explain how ideas gain momentum and diffuse through populations. The model achieves this by categorizing individuals into adoption stages (e.g., innovators, early adopters) and illustrating factors that influence the adoption of an innovation (e.g., relative advantage, compatibility) (41). Health practitioners can use this and similar models to design 
TABLE 1 | Examples illustrating Public Health Innovation Model (PHIM) and design thinking components.

\begin{tabular}{|c|c|c|c|}
\hline $\begin{array}{l}\text { Intervention } \\
\text { or program }\end{array}$ & Program details & PHIM stage with activity highlights & $\begin{array}{l}\text { Design thinking } \\
\text { component }\end{array}$ \\
\hline
\end{tabular}

Peterborough Based on the idea of a Social Impact Bond, where the government Cross-collaboration and community buy-in-Involves

Prison Bond only pays for a program if it meets a set of predetermined criteria of garnering support and buy-in from the private sector, who

(24-26) efficacy. Allows governments to try something new without the risk provides the initial capital

Empathy

of embarrassment or failure

Autonomy and Creativity - A unique, novel program to

reduce prison recidivism rates that encourages creativity and

independent solutions that have never been done before to

solve modern problems in modern ways

This program then partners with businessmen who are interested

Rapid Experimentation-Because the threat of breaking a

government contract is not present, individuals are able to in investing in social change to reduce prison recidivism rates. They provide the initial capital for these programs and then receive payment from the government after their idea successfully reduces the problem (7-13\% annual return on investment)

change course rapidly to meet population needs

Accountability - The programs are held accountable to their outcomes; if they don't prove they can solve the problem over time they are not funded

Code for This program involves "open sourcing the government," or

America- engaging citizens in caring for their communities from the ground

Adopt a Fire up using new technologies

Community Buy-In-Solutions are not created unless regular

citizens are not interested in and sold on ideas. People are

organized through initiatives online and work toward common goals through donated time

Hydrant (27)

People volunteer their time to create code to organize communities and solve social problems, such as coding an application that enables citizens to sign up to adopt fire hydrants near their residence

Cross-Collaboration-Organizations use resources and manpower from ordinary citizens to collaborate on social problems

Autonomy and Creativity-Adopt a Fire Hydrant uses twentyfirst century methods and online technology to organize and facilitate social change. There is no bureaucracy or hierarchy, as innovations come from the bottom-up

Rapid Experimentation and Prototyping - Little bureaucracy involvement means individuals are able to select problems and solutions as they see fit and act accordingly; can very quickly alter solutions and try out new ideas

Emphasis on Skills - Individuals are not necessarily required to have experience in public health or social fields; rather, an emphasis on coding skills is required for citizens to create solutions
Truth (28) A rebranded version of the hard-hitting Truth campaign, this campaign targets millennials in an attempt to make this the last generation to smoke in the United States

Using irreverent and targeted social media, viral videos, and events aimed at youth, this antismoking campaign is one of the few awareness campaigns utilizing the full capacity of Web 2.0
Cross-Collaboration and Community Buy-In - The campaign requires buy-in and engagement from teens to be successful, as the success of the campaign requires teens to share material on social media

Autonomy and Creativity - This campaign uses social media, a widely available and twenty-first century platform, to spread awareness and prompt action toward eliminating smoking. The interactive and open-source nature of social media enables youth to contribute ideas and exercise independence and creativity to decrease smoking prevalence

Emphasis on Skills - Important skills emphasized in this campaign not necessarily standard in public health include social media, marketing, and humor, among others

Rapid Experimentation-Campaign managers can instantly measure success, reach, etc. of individual promotional materials through social media metrics, allowing them to tailor messages

Community Buy-In - The potential planning was built on participants dream-sheet ideas to formulate plans that could be easily tested or prepared for some form of experimentation Cross-Collaboration and Community-Buy-In-Boeing used a forward-thinking question for innovation communicated through a virtual environment to foster creativity or innovation through the ideation strategy. In this case, social media allowed a broad group of participants whose ideas could emerge from everywhere in the world
Define and

ideate

Prototype

Test

Empathy

Empathy

Ideate

Prototype

Prototype

Empathy

Define and

ideate

Prototype

Prototype Empathy

World Design A co-creation contest (ideation) used to generate novel concepts and ideas. Some companies seek innovation by requesting target participants to complete a given task within a given timeframe

Boeing instituted a social media-based ideation to solicit 120,000 individuals around the world to be voluntary members of its World Design Team. Participants were invited to contribute their ideas to design a new 787 Dreamliner airplane

This example illustrates how virtual environments can foster creativity or innovation through the ideation strategy 
TABLE 1 | Continued

\begin{tabular}{|c|c|c|c|}
\hline $\begin{array}{l}\text { Intervention } \\
\text { or program }\end{array}$ & Program details & PHIM stage with activity highlights & $\begin{array}{l}\text { Design thinking } \\
\text { component }\end{array}$ \\
\hline \multirow[t]{3}{*}{$\begin{array}{l}\text { This City is } \\
\text { Going on a } \\
\text { Diet (30) }\end{array}$} & $\begin{array}{l}\text { Oklahoma City mayor, Mick Cornett was inspired to challenge his } \\
\text { city to lose one million pounds following his own 42-pound weight } \\
\text { loss. He partnered with fast food and local restaurants to promote } \\
\text { healthy menu choices }\end{array}$ & $\begin{array}{l}\text { Cross-Collaboration and Community-Buy-In-Was built by } \\
\text { connecting various players together rather than blaming. } \\
\text { Government leaders, retail merchants, and local citizens } \\
\text { became united around the message that "you have to eat } \\
\text { differently" }\end{array}$ & Empathy \\
\hline & $\begin{array}{l}\text { In early } 2007 \text {, the city began the challenge as one of the fattest } \\
\text { cities, and in early } 2012 \text {, it had met its million-pound goal and also } \\
\text { was listed among America's top } 10 \text { fittest cities }\end{array}$ & $\begin{array}{l}\text { Start-Up Funding-The mayor persuaded a healthcare } \\
\text { magnate to fund the information website, and local news } \\
\text { sources joined with their endorsements and support. Soon } \\
\text { national media became champions of the initiative }\end{array}$ & Prototype \\
\hline & $\begin{array}{l}\text { The innovation took hold because it focused on food intake and not } \\
\text { just exercise }\end{array}$ & $\begin{array}{l}\text { Community Testing-By emphasizing an inclusive message, } \\
\text { local participants tried different approaches with menu } \\
\text { planning to help improve a culture of good choices }\end{array}$ & Test \\
\hline
\end{tabular}

services and marketing efforts to increase appeal for targeted communities.

\section{Empathy and Assessment}

In traditional models, after capacity building, health practitioners typically enter the Assessment stage, gathering data and input from the target population, often in the form of a community health assessment. The corresponding design thinking mode is the Empathy mode. This mode involves the "effort to understand the way [populations] ... do things and why, their physical and emotional needs, how they think about the world, and what is meaningful to them" (10). While there is overlap between Empathy and Assessment, to better adopt the Empathy approach, public health practitioners may consider combining a humancentered approach with traditional assessment.

While data-driven approaches are crucial in community health assessments, a human-centered approach helps health practitioners to become more invested in the target population by promoting connection and more intimate interactions between health practitioners and those they serve. Such an approach can yield crucial insights into health problems that would not be possible with more formal approaches. Humancentered assessment may include more frequent face-to-face interactions with the target population, observing populations in their natural settings, approaching individuals with the intent to elicit stories as opposed to conduct interviews, and checking cultural biases.

\section{Define and Ideate}

After assessment in traditional public health models is the Planning stage. Generally, this entails researching evidence-based programs and adapting such programs for the target population.

In design thinking, the Define and Ideate modes correspond with Planning. The Define mode entails defining the right challenge to address based on new understanding of populations; it is "an endeavor to synthesize ... scattered findings into powerful insights" (10). Closely related is the Ideate mode, in which practitioners ideate potential solutions for the target population, often through brainstorming and other activities. In the Ideate mode, practitioners attempt to "step beyond obvious solutions," "harness the collective perspectives and strengths of ... teams," "create fluency (volume) and flexibility (variety) in ... innovation options," and "get obvious solutions out of [team members'] ... heads" (10). The Define and Ideate stage in the PHIM requires health practitioners to encourage autonomy and creativity in team members.

\section{Autonomy and Creativity}

Autonomy is a certain degree of freedom to test solutions and make decisions without fear of failure. The processes commonly used in the traditional public health planning model do not typically encourage creativity. First, public health professionals usually do not receive specific training to think creatively and innovatively. A reliance on evidence-based practice, while well meaning and useful in addressing familiar health challenges, is not appropriate when addressing the new or unfamiliar. Second, the evidence-based practice paradigm is generally based on the assumption that if a solution works in a handful of communities, it will work anywhere; more troubling still, many of the studies provided by organizations responsible for recommending evidence-based practice are out-of-date or infrequently updated.

To encourage health practitioners to act autonomously and creatively, program managers may consider encouraging workers to brainstorm ideas for the sake of generating insight into the problem at hand.

\section{Prototype}

In the traditional public health model, Planning is followed by Implementation. The corresponding design thinking mode is Prototyping. Prototyping is "the iterative generation of artifacts intended to answer questions that get you closer to your final solution" and includes creating "low-resolution prototypes that are quick and cheap to make ... but can elicit useful feedback from users and colleagues" (10).

In the Prototype mode, practitioners implement potential solutions with the goal to discover how they can improve their current model or program; in traditional Implementation, practitioners usually implement their programs full scale. The benefit of adopting the Prototype mode is that it allows health practitioners to better manage the solution-building process by breaking down problems and cheaply and quickly testing ideas (10). To adopt principles of the Prototype stage, 
public health practitioners must understand and implement the rapid experimentation and failure cycle characteristic of design thinking.

\section{Rapid Experimentation and Failure}

Rapid experimentation and failure are principles of success commonly found in the private sector, but not embraced in the current public health landscape due to limited funding opportunities. Intuit, a software company famous for their rapid experimentation framework, exemplifies the kinds of principles public health has the resources to implement on a microscale. At Intuit, employees are encouraged to generate innovative, even outrageous, ideas through building teams, gathering solutions, and creating and testing hypotheses. The key to Intuit's success lies in employees' ability to talk about ideas, test them quickly without spending exorbitant amounts of money, and have a healthy tolerance for failure (42).

In rapid prototyping, innovators iterate on theoretical and virtual prototypes until a "minimum awesome product" that "nails the pain" is created, as opposed to creating full-scale, error-free products that are expensive and require long development cycles (43). Despite differences between the products, audiences, and even motivations of the private and public sector, a mutually beneficial partnership between both sectors can develop on the basis of CSR. As stated previously, various private entities are motivated to engage in CSR for economic and ethical reasons. Public health practitioners can leverage the CSR component of the private sector for funds to initiate and sustain programs over time.

Furthermore, in public health, nailing the pain entails creating a health intervention or community plan that has enthusiastic buy-in from the community and is shown to change health outcomes. In traditional public health, such "prototyping" programs may take the form of pilot testing new ideas and conducting consumer research, but arguably, this is infrequently done in favor of evidence-based and traditional interventions, which are often required by granting organizations (44). Rapid prototyping allows for the testing of new ideas on a small-scale level and without extensive funding.

\section{Test and Outcomes}

After program implementation, health practitioners move to the Evaluation stage, which usually includes program impact and outcome evaluations. The corresponding design thinking stage is the Test mode, in which practitioners solicit feedback about the prototypes they created previously to refine prototypes, learn more about their target population, and refine their problem statement. The end goal of Testing is to get closer to an ideal solution. Results from the Test mode often prompt practitioners to go back to the Empathize, Define, Ideate, and Prototype modes to refine solutions, which is distinct from traditional public health models.

Evaluation is one of the essential skills needed for innovation (45). In design thinking, outcome evaluation, or whether a program or prototype elicited a significant change in outcomes, is the most important method of determining whether a prototype or program was successful. While process and impact evaluations in public health can be useful in determining program success, focusing too much time on this type of assessment may detract resources from evaluations that most clearly demonstrate success. The end goal is to begin to make public health entities more accountable to the programs they produce. While public health is already concerned with program evaluation, the PHIM promotes dispersing the final funding allocation after outcomes have been assessed and programs have proven to be successful. These key structural changes to the funding structure emphasize the importance of achieving measurable outcomes and perpetuating programs that are successful, while eliminating programs that fail to make significant changes.

A common evaluation approach used with the traditional public health planning model is the use of logic modeling to demonstrate how inputs result in outcomes. Although innovation typically occurs through cross-collaboration, "a simple input-output or cause-and-effect model of evaluation is not appropriate." (46) Newer, more sophisticated evaluation tools can be used when approaching evaluation from a systems thinking perspective. These tools can help with monitoring the interaction and connection between collaborators rather than simply the additive effects of inputs on outputs. Keane (47) has developed a tool to use "interactive" logic modeling to assess the impact of relationships (47). Capacity to conduct these types of evaluations will also continue to grow as more big data sources, such as electronic medical records, become available to public health.

\section{CONCLUSION}

Innovation is not intended to replace public health best-practices or planning models but is available to enhance those practices and tailor interventions to meet local needs. Traditional public health planning models are useful, but practitioners are more likely to promote innovation by allowing opportunities for building commitment, empathy, ideation, and prototyping. Further, it is feasible that more challenging issues, such as persistent chronic or infectious diseases, can be better addressed through innovation-driven creativity and greater cooperation.

The aim of learning effective innovations can only come when there is a reasonable willingness to accept failures as essential for making improvements. The notion of "good failures" can be difficult for practitioners and stakeholders to accept because failure is often viewed as the antithesis of success. However, the key to good failure is that it can accelerate the learning process. The value of the PHIM is its ability to identify the hypothetical 1 strategy out of 10 that works. Evaluation of innovation requires a different perspective and should be viewed as a learning opportunity to identify what really works rather than implementing a well-intentioned approach that ultimately may not achieve an impact, which commonly occurs in practice today. Even when only 1 approach in 10 demonstrates success, that 1 approach can certainly help to inform future practice and lead to more impactful intervention.

\section{AUTHOR CONTRIBUTIONS}

All authors contributed toward idea formulation and writing. 


\section{REFERENCES}

1. Centers for Disease Control and Prevention. Ten Great Public Health Achievements in the 20th Century. (2017). Available from: http://www.cdc. gov/about/history/tengpha.htm

2. Centers for Disease Control and Prevention. Achievements in public health, 1900-1999: changes in the public health system. MMWR (1999) 48(50):1141-7.

3. Lister C, Royne M, Payne HE, Cannon B, Hanson C, Barnes M. The laugh model: reframing and rebranding public health through social media. Am J Public Health (2015) 105(11):2245-51. doi:10.2105/AJPH.2015.302669

4. What Public Health Departments Need to Adopt Social Media. Emergency Management (2014). Available from: http://www.gcckc.com/gcc-news/ what-public-health-departments-need-to-adopt-social-media

5. Thackeray R, Neiger BL, Smith AK, Van Wagenen SB. Adoption and use of social media among public health departments. BMC Public Health (2012) 12(1):242. doi:10.1186/1471-2458-12-242

6. Healey BJ, Lesneski CD. Transforming Public Health Practice: Leadership and Management Essentials. San Francisco, CA: John Wiley \& Sons (2011). Available from: https://books.google.com/ books?hl=en\&lr=\&id=z_O-BS8b4ucC\&pgis $=1$

7. Herbold RJ. Seduced by Success: How the Best Companies Survive the 9 Traps of Winning. New York, NY: McGraw-Hill (2007).

8. Public Health Financing. CDC Website (2017). Available from: http://www. cdc.gov/stltpublichealth/docs/finance/public_health_financing-6-17-13.pdf

9. McKenzie JF, Neiger BL, Thackeray R. Planning, Implementing, \& Evaluating Health Promotion Programs: A Primer. New York, NY: Pearson Higher Ed (2017).

10. An Introduction to Design Thinking Process Guide. Institute of Design at Stanford (2017). Available from: https://dschool-old.stanford.edu/sandbox/ groups/dtbcresources/wiki/bdb3f/attachments/e3cfa/NewCity-FacilitatorsGuide-March2014-(V6).pdf?sessionID=8a36f7a15079a8053bd6f424e621f46 e9692f705

11. Design Thinking Processes. The K12 Lab Wiki (2009). Available from: https:// dschool.stanford.edu/groups/k12/wiki/781c0/Design_Thinking_Processes. html

12. Trowbridge M. Leveraging the Power of Design and Design Thinking for Public Health. Robert Wood Johnson Foundation (2013). Available from: http://www.rwjf.org/en/culture-of-health/2013/10/leveraging_the_ power.html

13. Hernandez-Aguado I, Zaragoza GA. Support of public-private partnerships in health promotion and conflicts of interest. BMJ Open (2016) 6(4):e009342. doi:10.1136/bmjopen-2015-009342

14. Galea G, McKee M. Public-private partnerships with large corporations: setting the ground rules for better health. Health Policy (2014) 115(2):138-40. doi:10.1016/j.healthpol.2014.02.003

15. Roehrich JK, Lewis MA, George G. Are public-private partnerships a healthy option? A systematic literature review. Soc Sci Med (2014) 113:110-9. doi:10.1016/j.socscimed.2014.03.037

16. History. Sorensen Impact Center (2017). Available from: http://sgiicenter. com/history/

17. Medicines for Malaria Venture. Medicines for Malaria Venture (2017). Available from: http://www.mmv.org/

18. The Bill \& Melinda Gates Foundation, Merck \& Co., Inc. and the Republic of Botswana Launch New HIV Initiative. The Bill \& Melinda Gates Foundation (2000). Available from: http://www.gatesfoundation.org/Media-Center/ Press-Releases/2000/07/Comprehensive-HIVAIDS-Partnership

19. European Commission. Green Paper: Promoting a European Framework for Corporate Social Responsibility. Office for Official Publications of the European Communities (2001). Available from: http://europa.eu/rapid/ press-release_DOC-01-9_en.htm

20. Caring Dairy. Ben and Jerry's (2017). Available from: http://www.benjerry. com/caringdairy

21. Water Less $^{\mathrm{TM}}$. Levi Strauss \& Co (2017). Available from: http://levistrauss. com/sustainability/products/waterless/

22. About TOMS. TOMS (2017). Available from: http://www.toms.com/ corporate-responsibility
23. Orlitzky M, Schmidt FL, Rynes SL. Corporate social and financial performance: a meta-analysis. Organ Stud (2003) 24(3):403-41. doi:10.1177/ 0170840603024003910

24. International Development: What If You Could Invest in Development? Social Finance (2017). Available from: http://www.socialfinance.org.uk/impact/ international-development/

25. CriminalJustice.SocialFinance(2017).Availablefrom:http://www.socialfinance. org.uk/impact/criminal-justice/

26. Quoted: Toby Eccles on the Results of the Peterborough Prison Pilot. TEDBlog (2017). Available from: http://blog.ted.com/quoted-toby-eccles-on-thepeterborough-prison-pilot/

27. Adopt-a-Hydrant. Adopt-a-Hydrant (2017). Available from: http://www. adoptahydrant.org/

28. Truth. The Truth (2017). Available from: https://www.thetruth.com/

29. Boeing. Boeing (2017). Available from: http://www.boeing.com/

30. OKC Million Update. 1,000,000 Pounds Lost!. Healthwise Communities (2015). Available from: http://okc.healthwisechampions.com/\#my-journal

31. Valente TW, Chou CP, Pentz MA. Community coalitions as a system: effects of network change on adoption of evidence-based substance abuse prevention. Am J Public Health (2007) 97(5):880-6. doi:10.2105/ AJPH.2005.063644

32. Leischow SJ, Milstein B. Systems thinking and modeling for public health practice. Am J Public Health (2006) 96(3):403-5. doi:10.2105/ AJPH.2005.082842

33. Leischow SJ, Best A, Trochim WM, Clark PI, Gallagher RS, Marcus SE, et al. Systems thinking to improve the public's health. Am J Prev Med (2008) 35(2):S196-203. doi:10.1016/j.amepre.2008.05.014

34. Flicker S, O'Campo P, Monchalin R, Thistle J, Worthington C, Masching R, et al. Research done in "a good way": the importance of indigenous elder involvement in HIV community-based research. Am J Public Health (2015) 105(6):1149-54. doi:10.2105/AJPH.2014.302522

35. Oetzel JG, Villegas M, Zenone H, White Hat ER, Wallerstein N, Duran B. Enhancing stewardship of community-engaged research through governance. Am J Public Health (2015) 105(6):1161-7. doi:10.2105/AJPH.2014. 302457

36. Beattie TS, Mohan HL, Bhattacharjee P, Chandrashekar S, Isac S, Wheeler T, et al. Community mobilization and empowerment of female sex workers in Karnataka State, South India: associations with HIV and sexually transmitted infection risk. Am J Public Health (2014) 104(8):1516-25. doi:10.2105/ AJPH.2014.301911

37. Fawcett SB, Sepers CE, Jones J, Jones L, McKain W. Participatory evaluation of a community mobilization effort to enroll Wyandotte County, Kansas, residents through the Affordable Care Act. Am J Public Health (2015) 105(S3):S433-7. doi:10.2105/AJPH.2014.302505

38. Easterly W, Easterly WR. The White Man's Burden: Why the West's Efforts to Aid the Rest Have Done so Much Ill and so Little Good. Oxford, NY: Oxford University Press (2006).

39. Lépine A, Lagarde M, Le Nestour A. Free primary care in Zambia: an impact evaluation using a pooled synthetic control method. SSRN (2014). doi: $10.2139 /$ ssrn. 2520345

40. Litvack JI, Bodart C. User fees plus quality equals improved access to health care: results of a field experiment in Cameroon. Soc Sci Med (1993) 37(3):369-83. doi:10.1016/0277-9536(93)90267-8

41. Rogers EM. A prospective and retrospective look at the diffusion model. J Health Commun (2004) 9(S1):13-9. doi:10.1080/10810730490271449

42. Next Tool. Intuit (2016). Available from: http://intuitlabs.com/wp-content/ uploads/2014/12/next_tool.pdf

43. Furr N, Christensen CM, Dyer J. The Innovator's Method: Bringing the Lean Start-up into Your Organization. Harvard Business Press (2014). Available from: https://books.google.com/books?hl=en\&lr=\&id=BQEQBAAAQBAJ\& pgis $=1$

44. Jacobs JA, Jones E, Gabella BA, Spring B, Brownson RC. Tools for implementing an evidence-based approach in public health practice. Prev Chronic Dis (2012) 9:110324. doi:10.5888/pcd9.110324

45. Levy M, Gentry D, Klesges LM. Innovations in public health education: promoting professional development and a culture of health. Am J Public Health (2015) 105(S1):S44-5. doi:10.2105/AJPH.2014.302351 
46. Perrin B. How to - and how not to - evaluate innovation. Evaluation (2002) 8(1):13-28. doi:10.1177/1358902002008001514

47. Keane C. Modeling Behavior in Complex Public Health Systems: Simulation and Games for Action and Evaluation. Springer Publishing Company (2013). Available from: https://books.google.com/books?hl=en\&lr=\&id=rWKAAAAQBAJ\&pgis $=1$

Conflict of Interest Statement: The authors declare that the research was conducted in the absence of any commercial or financial relationships that could be construed as a potential conflict of interest.
HP and CL, former students at BYU, are now employees of Epic. The article was written while they were students in the MPH program at BYU. All other authors declare no competing interests.

Copyright (c) 2017 Lister, Payne, Hanson, Barnes, Davis and Manwaring. This is an open-access article distributed under the terms of the Creative Commons Attribution License (CC BY). The use, distribution or reproduction in other forums is permitted, provided the original author(s) or licensor are credited and that the original publication in this journal is cited, in accordance with accepted academic practice. No use, distribution or reproduction is permitted which does not comply with these terms. 